\section{Check-List of Birds of the World}

Vol. 9. Edited by Ernst Mayr and James C. Greenway, Jr. (A Continuation of the Work of James L. Peters.) Pp. xii +506. (Cambridge, Mass. : Museum of Comparative Zoology; Copenhagen: Zoological Museum, 1960.) 7.50 dollars.

$\mathrm{T}$ HIS is the basic modern work in systematic ornithology and was planned for fifteen volumes. Of these, Volumes 1-7 appeared in the period 19311951 and covered all the non-passerine birds and a few families of passerines. The death of Peters in 1952 , with only a little more material ready in manuscript, made new arrangements necessary for completion. The editors appointed by the Museum of Comparative Zoology at Harvard are E. Mayr and J. C. Greenway, jun., and they have proceeded on the plan of apportioning the groups among selected specialists in America and Europe. This should speed up the issue of the remaining volumes, which will appear when ready and not in numerical sequence.

Volume 9 is thus the first to appear under the new arrangements. It covers a dozen passerine families of varying distribution-some cosmopolitan (for example, swallows), some purely old World (bulbuls, etc.), some purely New World (for example, mockingbirds), and some very restricted (such as the vangas, peculiar to Madagascar). Each familial section has its own author, and other systematists who have read the manuscript in a consultative capacity are named in addition. The information given consists of the scientific names (with references) of each species and each sub-species thereof, and the distribution of each form.

The resumption of publication of this important work is most welcome, and on the new co-operative basis of authorship one may hope for early completion. One may then look forward to revised editions of some of the earlier volumes which are out of print as well as in parts out of date.

Landsborough Thomson

\section{Institut National des Sciences et Techniques Nucléaires}

Symposium de Métallurgie Spéciale organisé à Saclay les 27 et 28 Juin 1957 par le Département de Métal. lurgie et de Chimie Appliquée. Pp. iv +128. (Gifsur-Yvette (S.-et-O.) : Centre d'Études Nucléaires de Saclay; Paris: Presses Universitaires de France, 1958.) n.p.

A $\mathrm{S}$ the title suggests, this symposium concerned A particular problems in nuclear metallurgy. Certain of the papers are transcriptions of previous published work. Naturally enough, the majority originate in France, but there are four outside contributions, from Holland, Sweden and Great Britain.

The main topic of the symposium is occupied with allotropic transformations, recrystallization and textures which result.

The transformations in uranium and zirconium and their various alloys are discussed from several aspects. One paper makes a comparison between uranium and iron.

The work on recrystallization and polygonization is treated from a variety of angles, and examples are illustrated from magnesium, aluminium, zirconium, cobalt and titanium, or alloys based on these metals.

As usual, some beautiful micrographs are reproduced, particularly those by Prof. P. Lacombe on polygonization in uranium, and the examination of alpha structures in uranium by Mme. Lehmann and
H. Aubert. There is an interesting report on mechanical properties of magnesium-zirconium alloys which is relevant to British work soon to be reported by the Institute of Metals.

The discussion is included at the end of each paper, and the proceedings commence and terminate with the speeches of welcome and conclusion presented at the time.

C. R. Tottle

\section{Sonderausschuss Radioaktivität}

Bundesrepublik Deutschland, Zweiter Bericht, März 1959. Pp. 117. (Stuttgart: Georg Thieme Verlag, 1959.) 12.60 D.M

A $\mathrm{N}$ impressive organization for measuring the $A$ contamination by radioactive materials has been set up in West Germany. The reported data for 1958 show a wealth of measurements of the concentration in the air near the surface, in water from different sources, in the soil, in plants, animals and bones of humans. Comparison of the data for 1958 with those of previous years shows no significant increase. An attempt to predict the increase in fall-out if testing of nuclear weapons is either discontinued or if it proceeds at the rate of the year under review indicates that substantial increases are to be expected. A survey of the results of the German film protection service shows that nearly 10 per cent of persons engaged in work connected with ionizing radiation receive doses of more than $0.4 \mathrm{r}$. per month. In future reports an estimate of the amounts of radiation received by patients in hospitals would complete an otherwise admirable survey. The data are set out in great detail in a large number of well-designed tables. S. R. PelC

\section{Linear and Stereoregular Addition Polymers}

Polymerization with Controlled Propagation. By Norman G. Gaylord and Herman F. Mark. (Polymer Reviews, Vol. 2.) Pp. $\mathrm{x}+571$. (New York: Interscience Publishers, Inc.; London: Interscience Publishers, Ltd., 1959.) $135 s$.

THE recent discovery of methods of synthesis of sterically regulated polymers is not only of fundamental scientific interest but also has opened up possibilities for far-reaching commercial application. Since Zeigler's spectacular discovery of the catalysts for the low-pressure polymerization of ethylene, and Natta's brilliant syntheses of stereoregular hydrocarbon polymers, an immense amount of research has been carried out during the past six years in scientific and industrial laboratories in Europe, the United States and Asia. This book summarizes systematically publications up to February, 1959, and also correlates the various characteristic features of the new processes. With the avalanche of new work being published it was a very noble task for the authors to attempt such a review. Much of the newer work is contained in an enormous number of patents, and since these still remain the most abundant source of information the chapter summarizing some 500 patent examples is one of the most valuable in the book.

While much more remains to be discovered about the mechanism of Zeigler catalysis and the nature of stereospecific polymerization, this book is the best source of information available. The authors have done a great service to polymer chemists in presenting a comprehensive and authoritative source of information on this new branch of polymer science.

C. E. H. BAwN 